كلمة التحرير

\title{
المنهج وما وراء المنهج: قولٌ على قولٍ
}

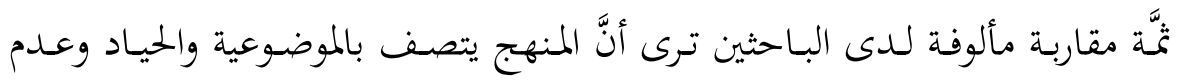

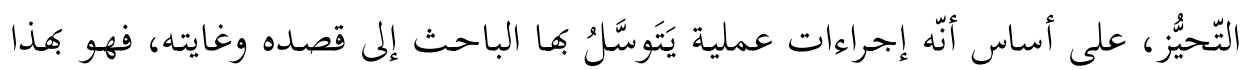

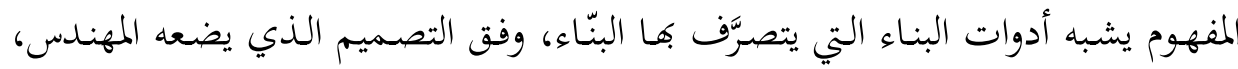

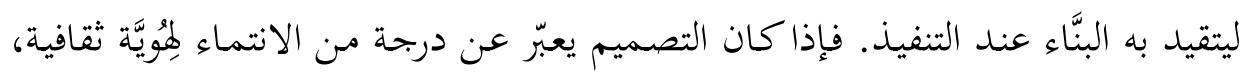

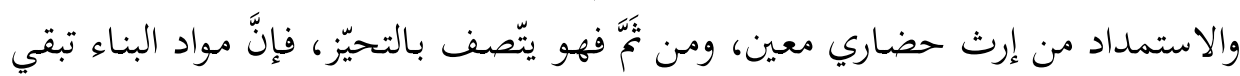

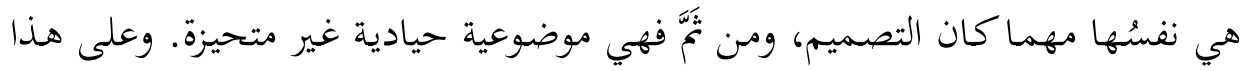

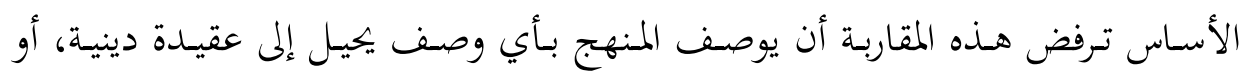

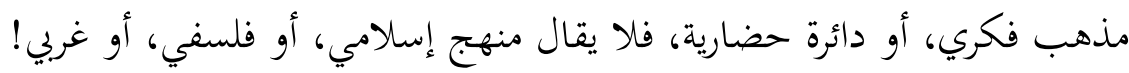

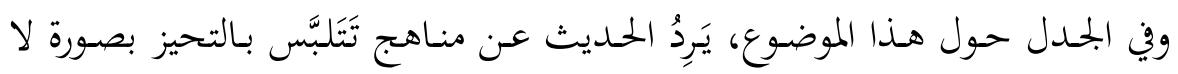

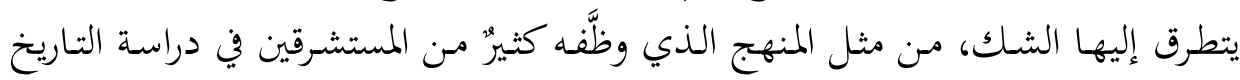

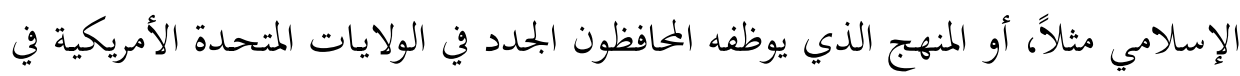

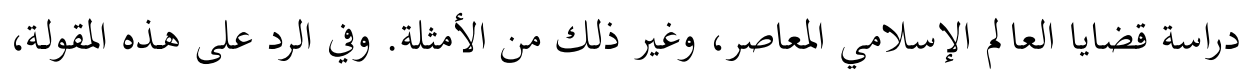

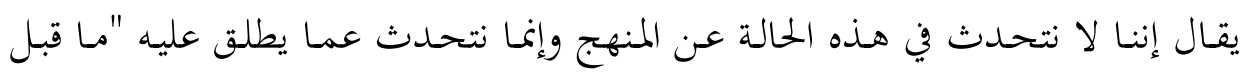

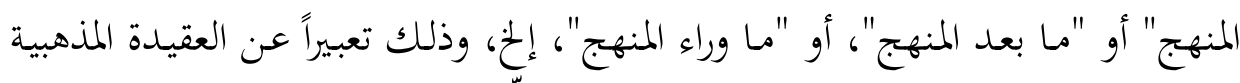

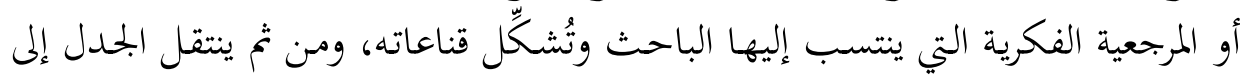

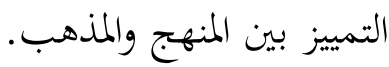

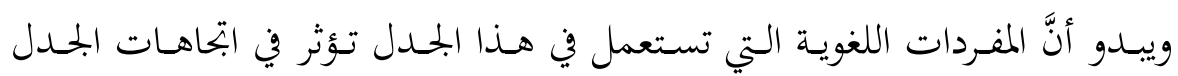

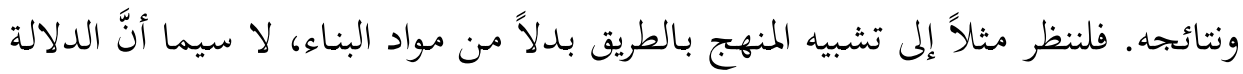

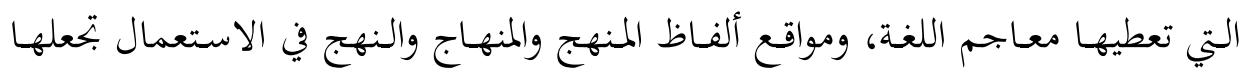

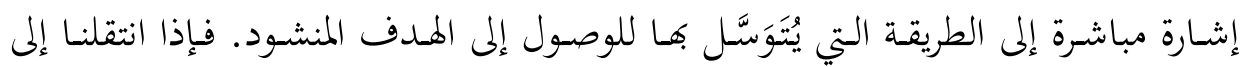

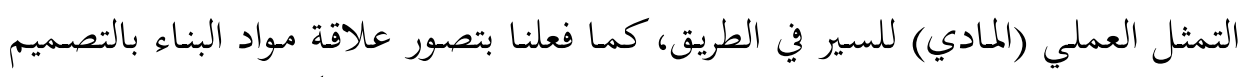

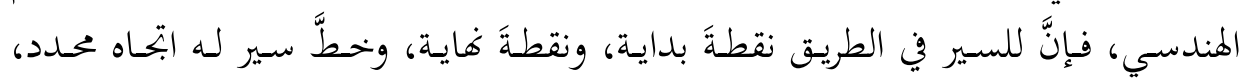
وعندها سيكون السؤال عن مدى تأثير كلٍٍ من نقطة البداء في المسير ونقطة الانتهاء 


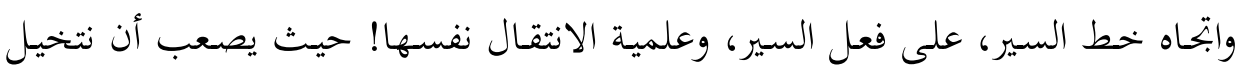

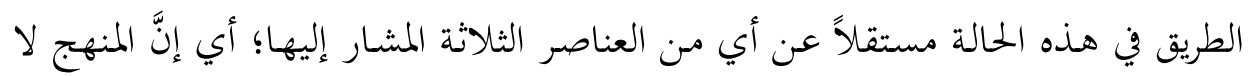

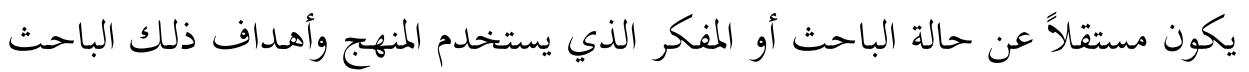
أو المفكر.

ثم إنَّ الجحدل يمكن أن ينتقل من الحديث عن مفهوم المنهج بوصفه طريقاً أو وسيلة، إنها،

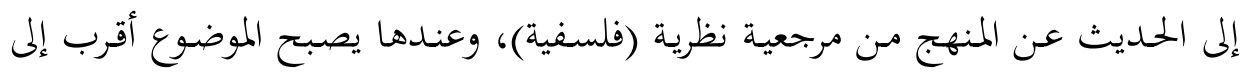

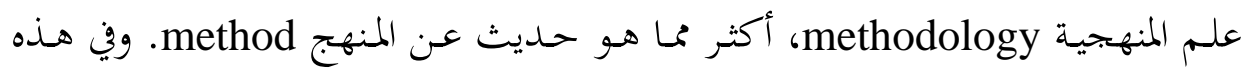

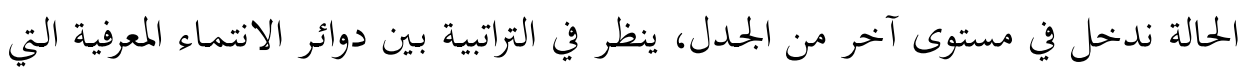

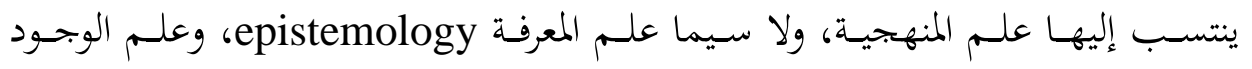

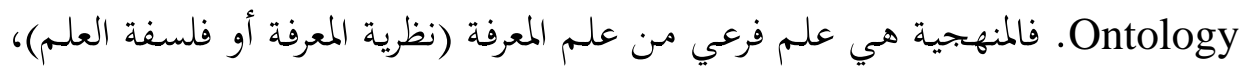

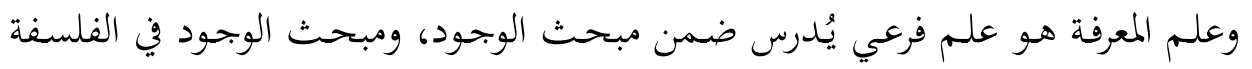

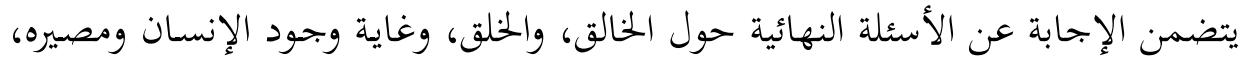

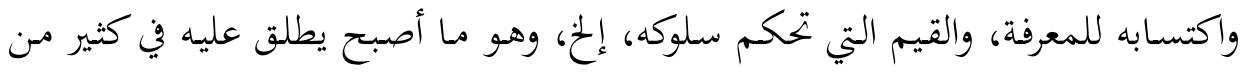

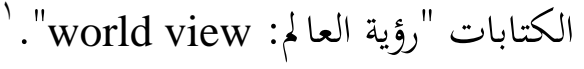

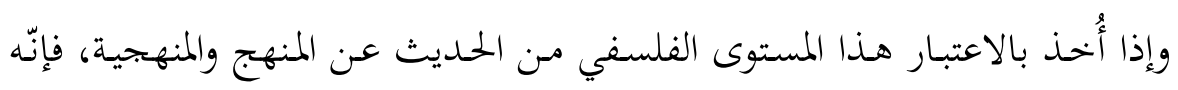

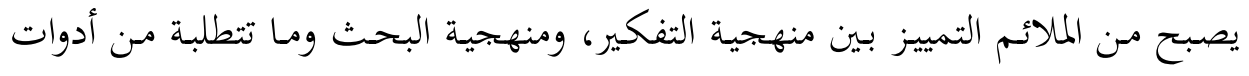

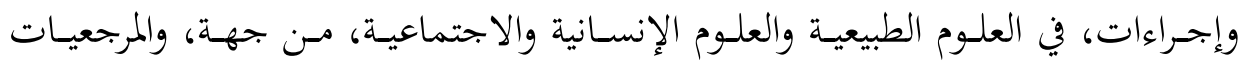

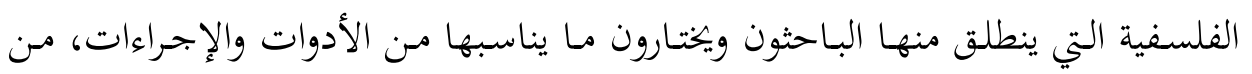

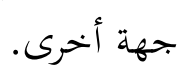

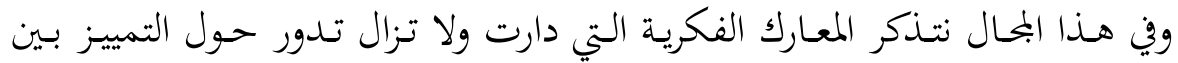

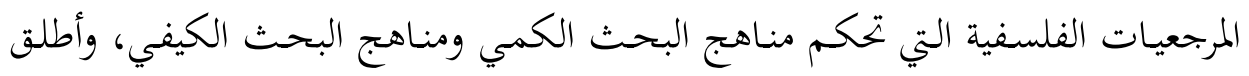

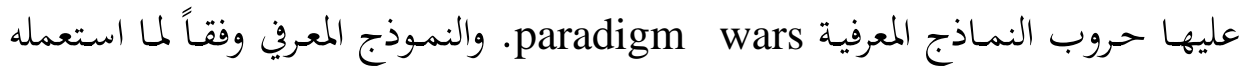

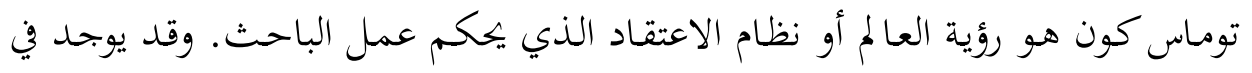

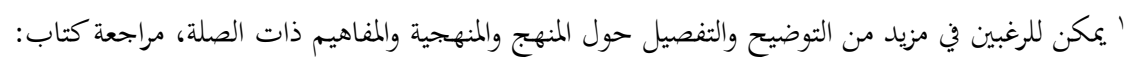

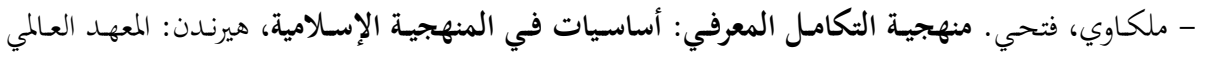




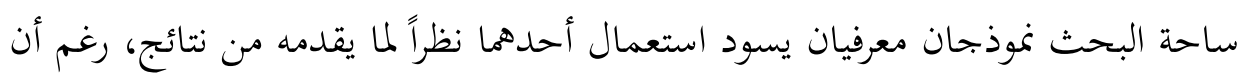

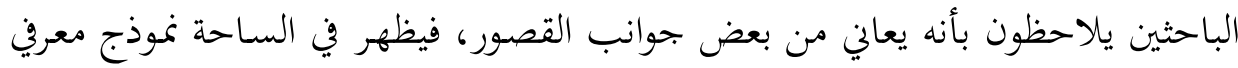

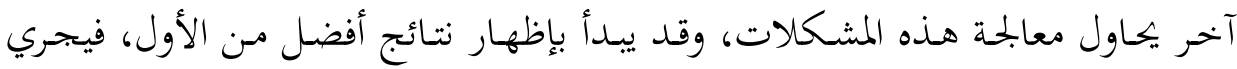

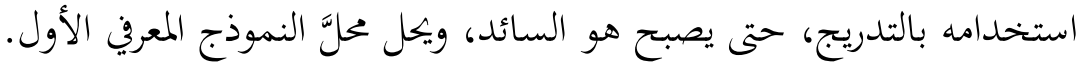
ومسن المعروف أنّ منـاهج البحـث التجـيبي التي مارسـها العلمـاء في ميـادين العلوم

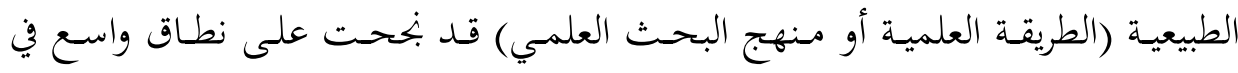
اكتشاف كثير من القوانين والنظريات والتطبيقات العملية، ولذلك بدأ الباحثون في العلوم

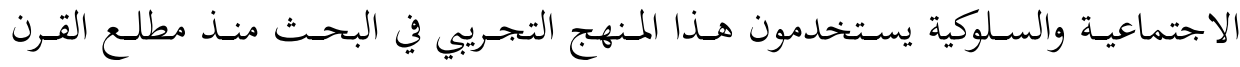

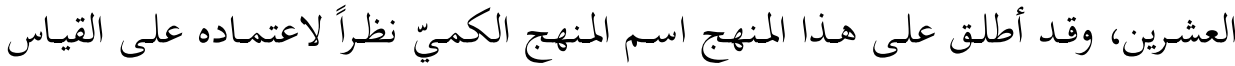

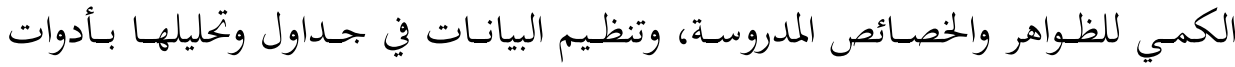

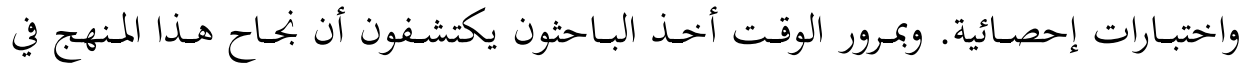

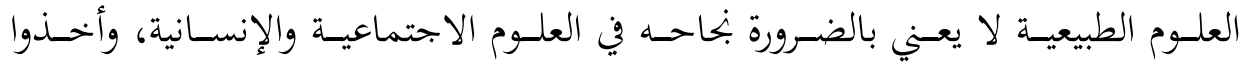

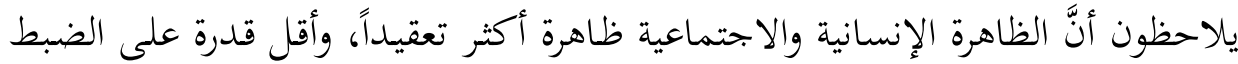

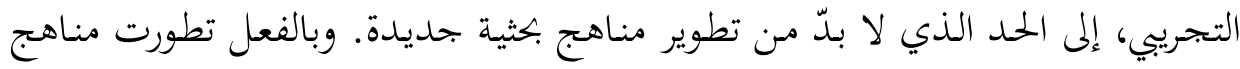

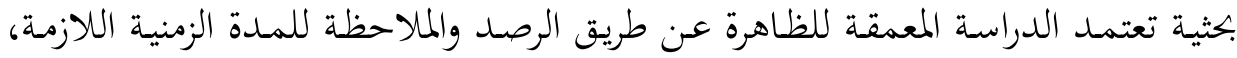

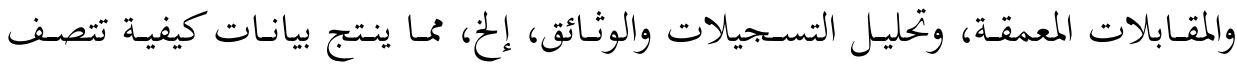

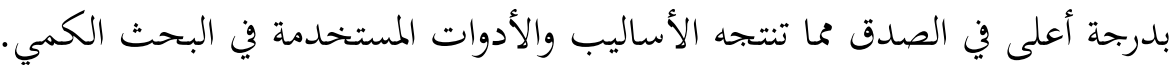
ولا ننسى في هـذا المقــام أن تحديـد الأسـاليب والأدوات البحثيـة التي تكـون أكثـر

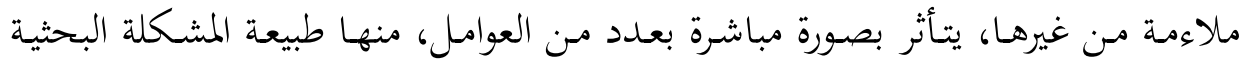

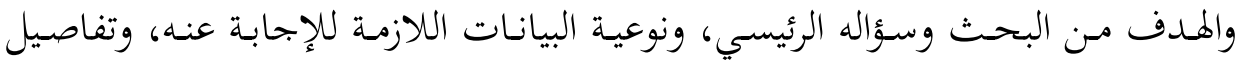

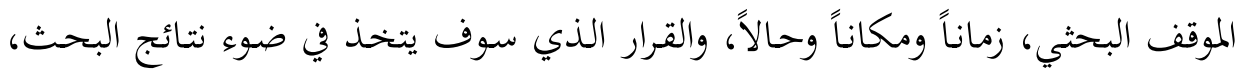

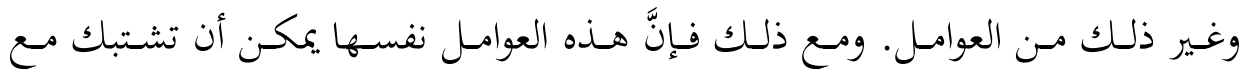

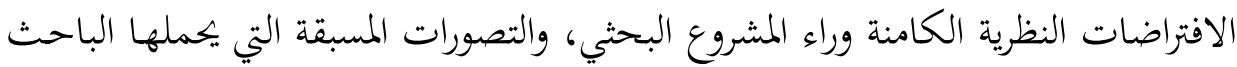

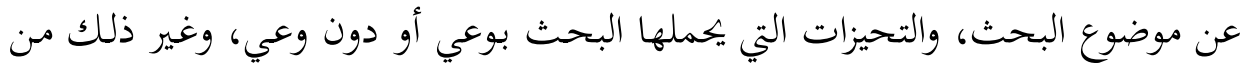

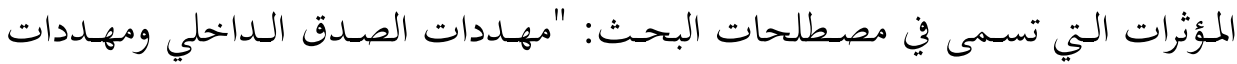




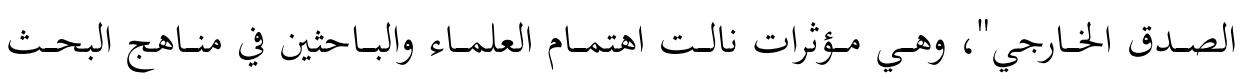
لتطوير إجراءات لمعالجتها.

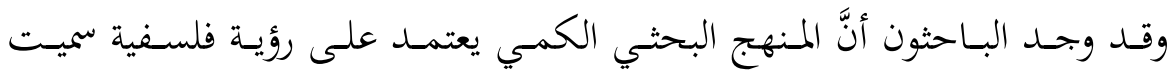

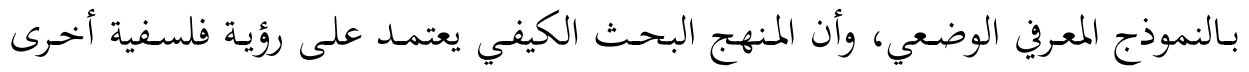

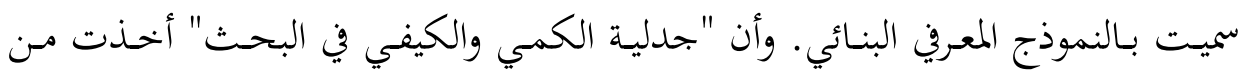

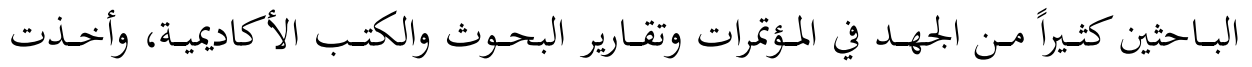

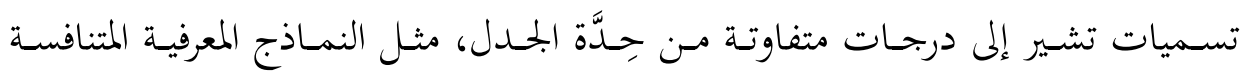
clash of أو competing paradigms

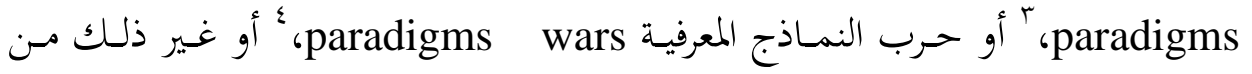
التسميات. وقد استخدمت هذه المصطلحات في مراجع شملت علوماً يختلفة من التربية

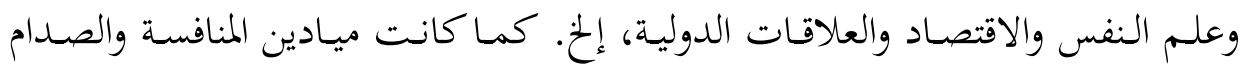
والحرب في قضايا مفاهيمية مهمة مثل طبيعة الحقيقة، والعلاقة السببية.

ولبيان عمق الاختلاف في المرجعية الفلسفية بين النموذجين الوضعي والبنائي، يمكن

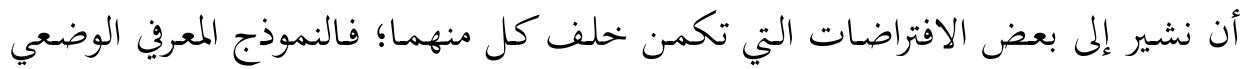

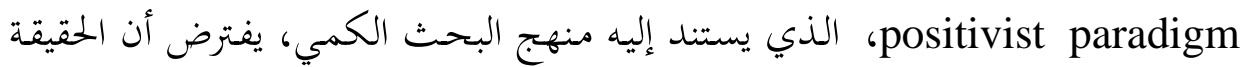
واحدة، وأن المعرفة مستقلة تماماً عن الشخص العارف، وأن منهج البحث لا يحمل بُعْداً

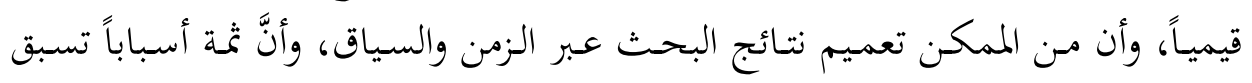

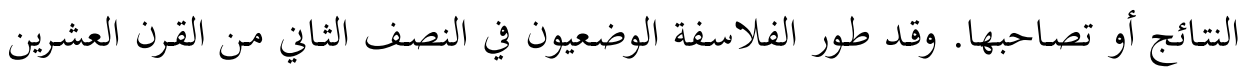

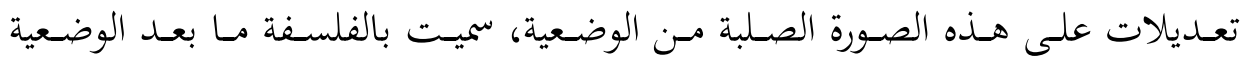

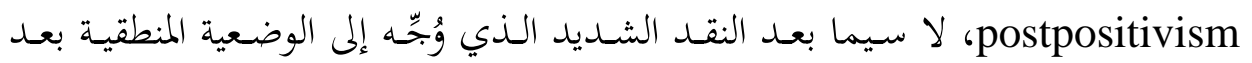
الحرب العالمية الثانية.

${ }^{2}$ Peercy, Chavanne. Local Leadership in Democratic Transition: Competing Paradigms in International Peace building, Palgrave Macmillan, 2013

${ }^{3}$ Maiava, Susan L. A Clash of Paradigms: Intervention, Response and Development in the South Pacific, Ashgate Pub Ltd, 2001.

${ }^{4}$ Woodhouse, Mark. Paradigm Wars: Worldviews for a New Age, Frog Books, 1996. 
وفي المقابل فإنَّ الافتراضات النظرية للنموذج المعرين البنائي -الذي يستند إليه المنهج

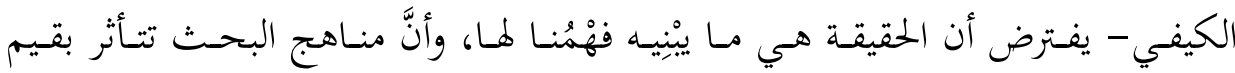

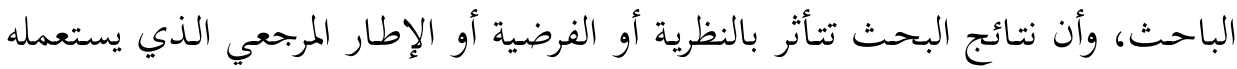
الباحث.

إننـا لا بنحـد مسـوغاً لأن نحصر مفهـوم المـنهج في الطريقـة أو العمليـة الإجرائيـة التي

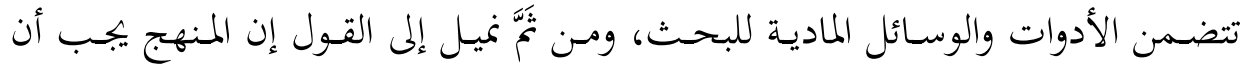

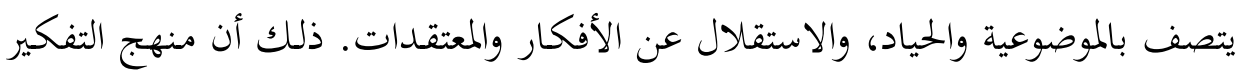

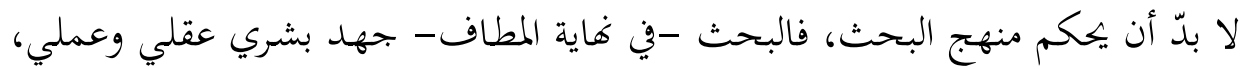

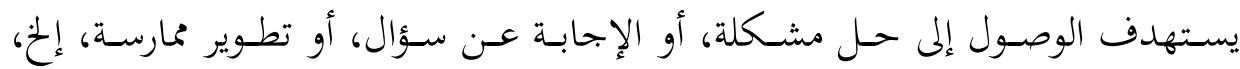

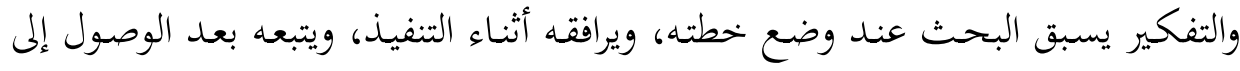

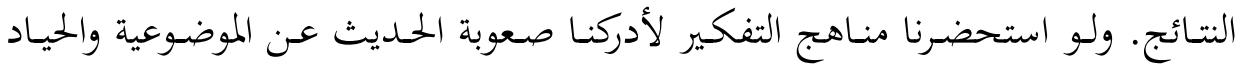

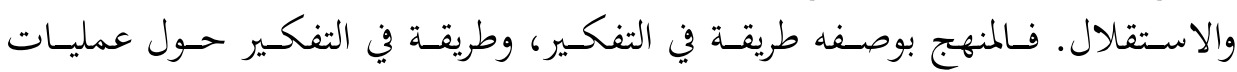

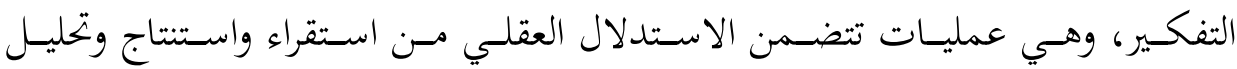

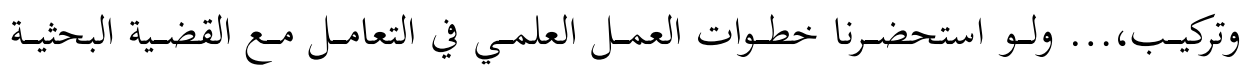

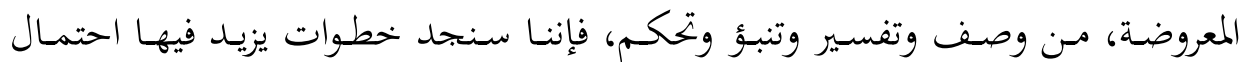

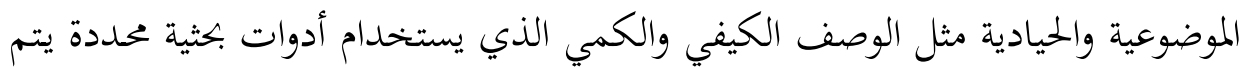

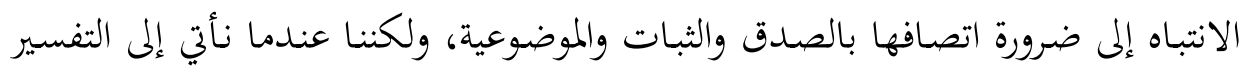

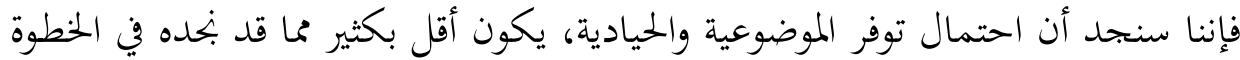

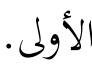

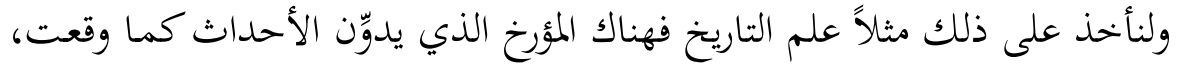

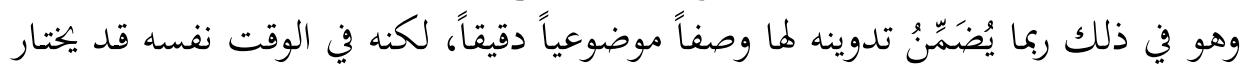

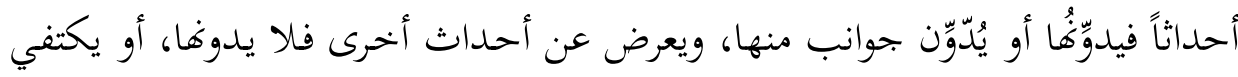

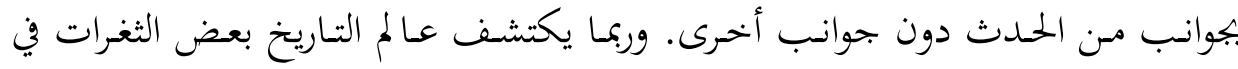

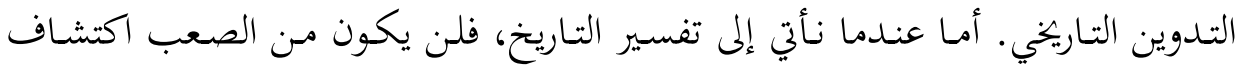

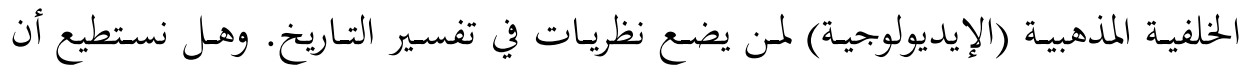

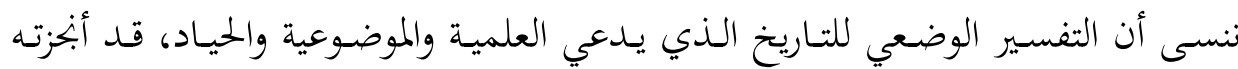

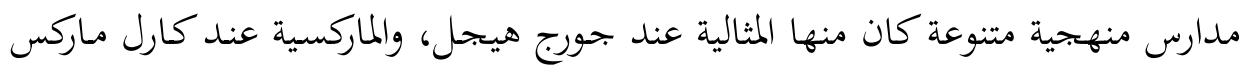




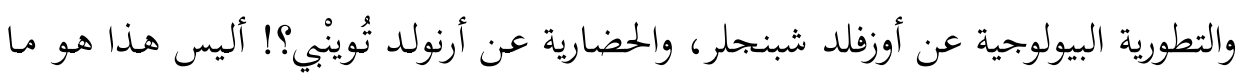

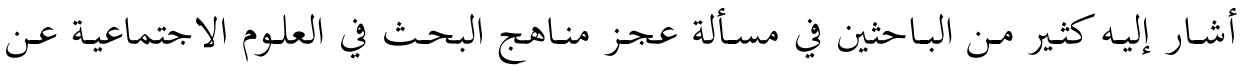

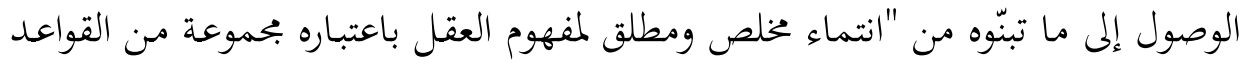

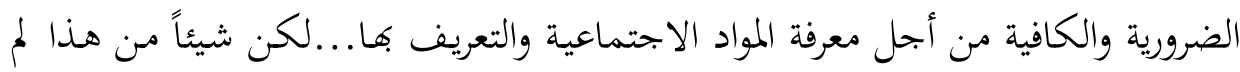

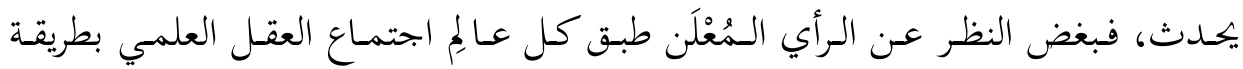

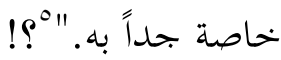

ولنأخــ مـثلاً آخـر. في تفسيره لظـاهرة عـدم قيـام البـاحثين العرب بإبهـاز دراسـات

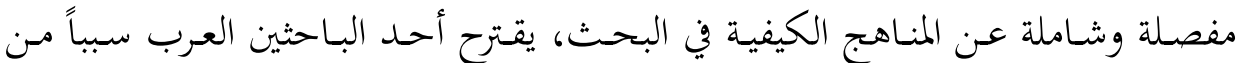

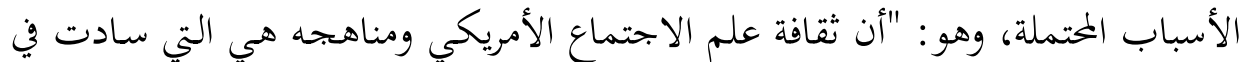

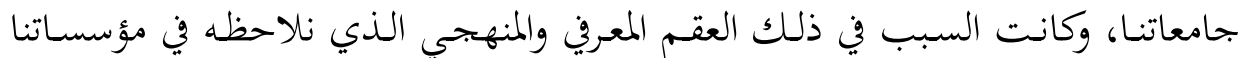
العلمية." الحساتنا"

وكان يُتوقع من الباحث الكريم أن يؤكد خطورة استيراد الثقافة المنهجية الأمريكية،

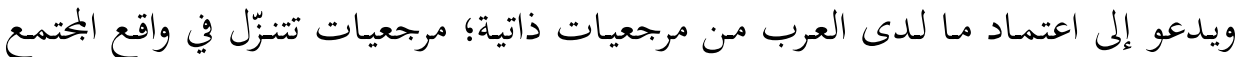

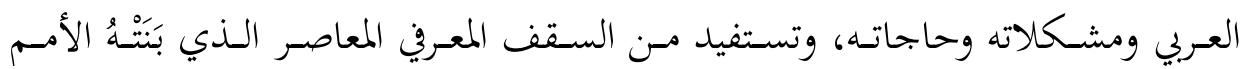

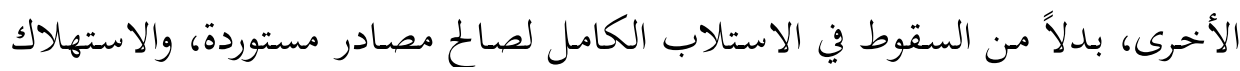

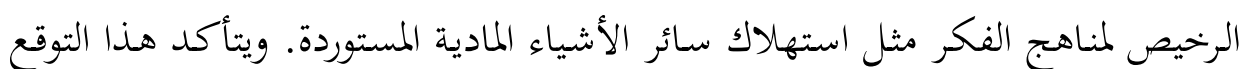
حين بند الباحث قد أقام النكير كذلك على المنهج الوضعي الذي طوره أوجست كونت

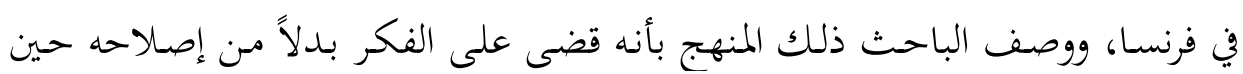
دعا إلى اعتماد منهج العلوم الطبيعية في دراسة علم الاجتماع.

لكن المفاجـأة هي أن الباحث نفسه الذي يرفض استيراد كل مـن الفكر المنهجي

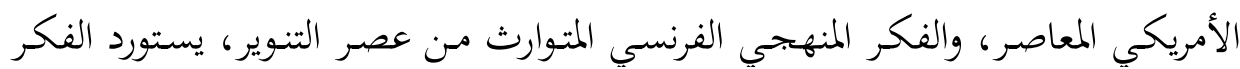

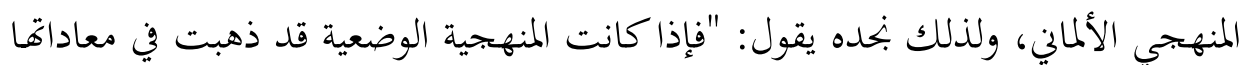

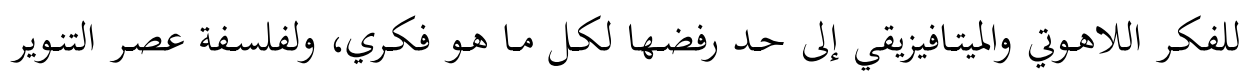
• بوسينو، جيوفاني. نقد المعرفة في علم الاجتماع، ترجمة: محمد عرب صاصيلا، بيروت: المؤسة الجامعية للدراسات

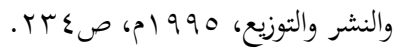

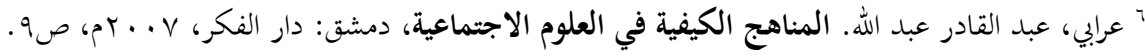




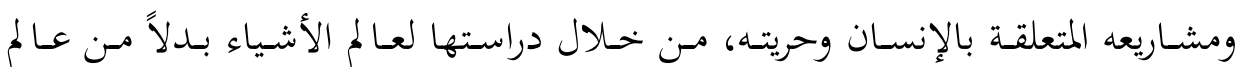

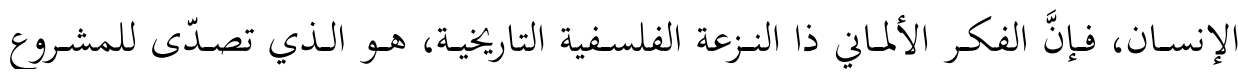

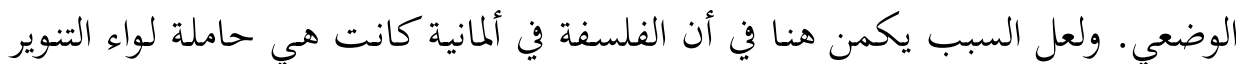

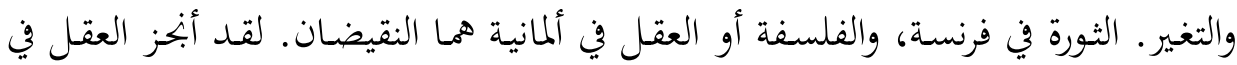

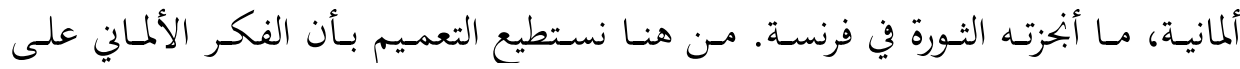

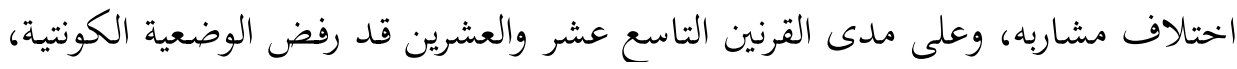

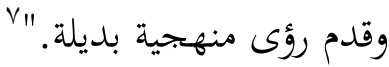

كيف يمكن تفسير هذه النمط من الفكر؟! إذا علمنا أنّ الباحث العربي الكريم قد

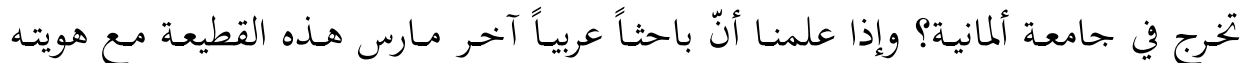

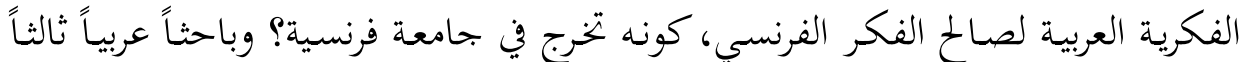

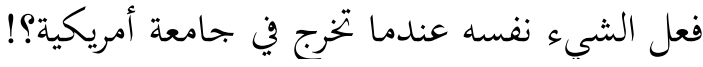
لماذا يقبل مثل هؤلاء هذا الهوان، حين يرون انتساكم لأمة، أو تاريخ، عبئًاً يثقل

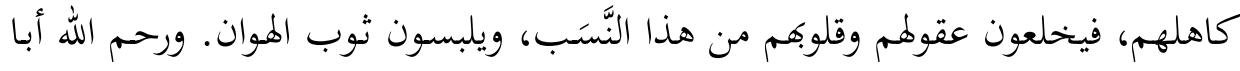

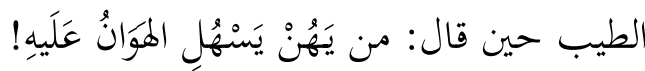

يتضمن هـا العدد بحوثاً تتصل بالمنهجية؛ إذ جاء البحث الأول بعنوان "المبادئ

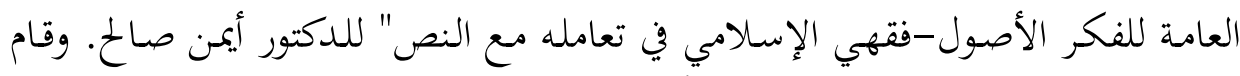

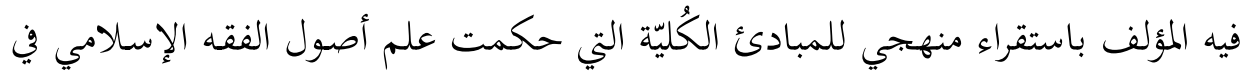

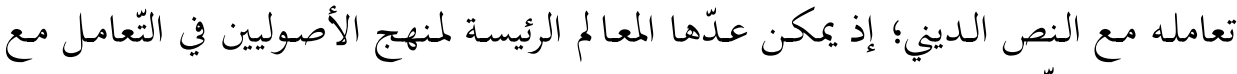

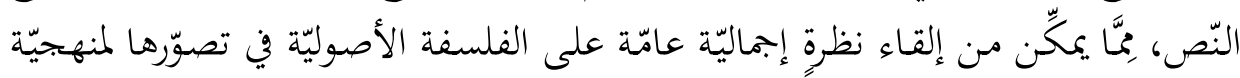
تلقي النّص والوصول إلى مكامنه.

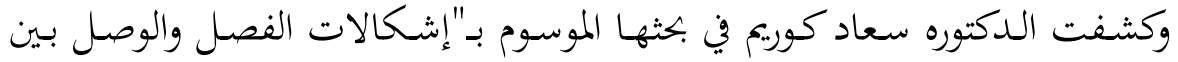

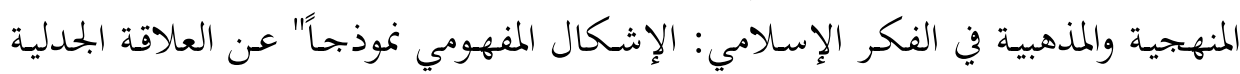

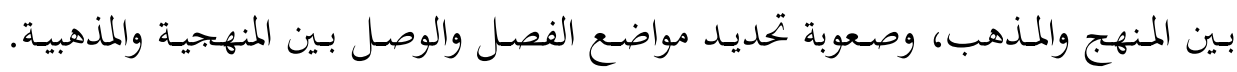

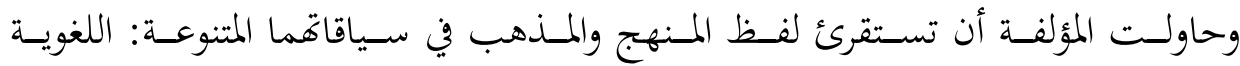




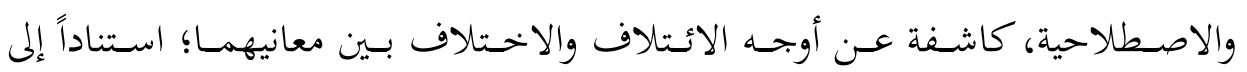

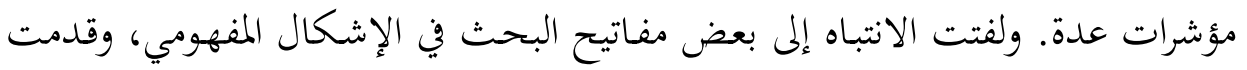

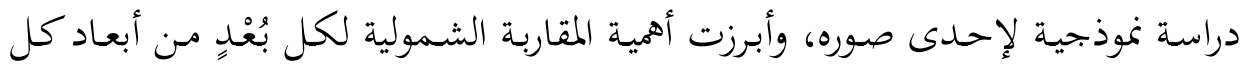

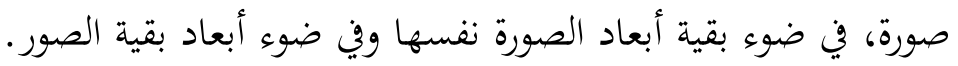

وسعى البحث الموسوم بـ"نو صياغة الأصول النظرية للحسبة العلمية في الإسلام:

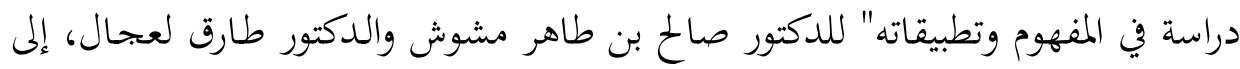

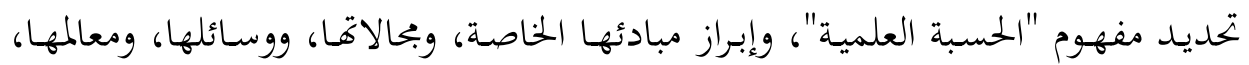

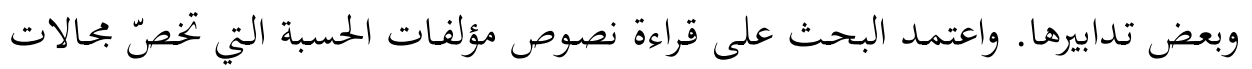

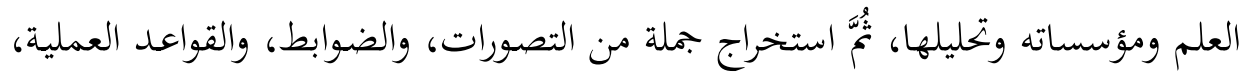
ونماذج في إدارة المؤسسات العلمية، وفق منظومة الحسبة العلمية. وقـام الدكتور بليـل عبد الكريم في بحثـه المعنون بـ"مسألة تزاحم الأحكام في تقييم

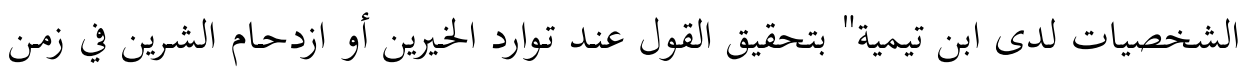

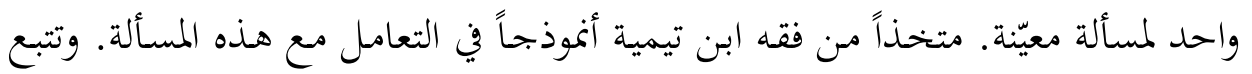

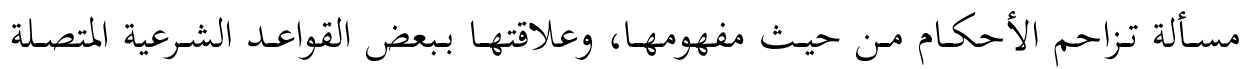

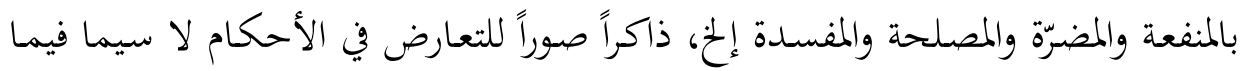
يتصل بتقييم الشخصيات الإسلامية.

وتضمن العدد كذلك مراجعتين؛ كانت الأولى لكتاب: "الحضارة الإسلامية: أسباب

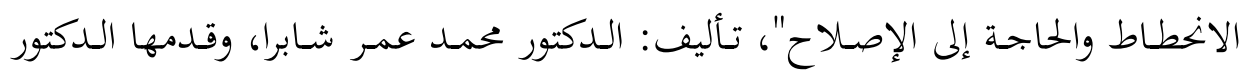

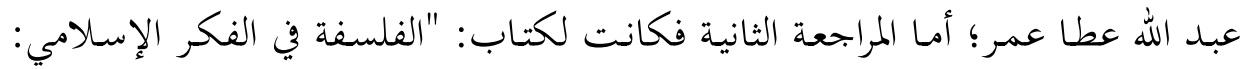
قراءة منهجيـة ومعرفيـة"، تحريـر: الـدكتور رائـد جميـل عكاشـة وآخـرون، وقـدمها الـدكتور عيسى ربيح أمين. واحتوى العدد على تقرير لمؤتمر: الإعلام المعاصر في الرؤية الحضارية.

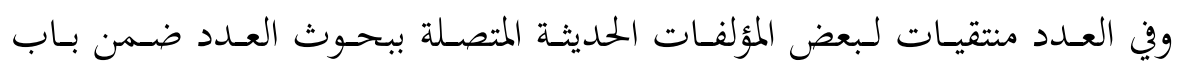
عروض مختصرة. والله ولي التوفيق. 